LBL--30071

DE91 014622

\title{
An Induction Linac Injector for Scaled Experiments*
}

\author{
H.L. Rutkowski, A. Faltens, C. Pike, D. Brodzik, R.M. Johnson and D. Vanecek \\ iawrence Berkeley Laboratory, \\ University of California \\ Berkeley, CA 94720
}

April 1991

This report has been reproduced directly from the best available copy.

* Work supported by the Director, Office of Energy Research, Office of Basic Energy Sciences, Advanced Energy Projects Division, U.S. Departmeni of Energy under Cunt det No. DE-AC03-76SF00098.

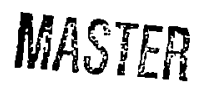




\title{
An Induction Linac Injector for Scaled Experiments*
}

\author{
H.L. Rutkowski, A. Faltens, C. Pike, D. Brodzik, R.M. Johnson, D. Vanecek, and D.W. Hewett** \\ Lawrence Berkeley Laboratory, \\ University of Califomia \\ Berkeley, Câifomia 94720
}

\begin{abstract}
An injector is being developed at LBL that would serve as it the front end of a scaled induction linac acceleralor technology experiment for heavy ion fusion. The ion mass being used is in the range 10-18. It is a multi-beam device intended to accelerate up to $2 \mathrm{MeV}$ with $500 \mathrm{~mA}$ in each beam. The first half of the accelernting column has been built and experiments with one carbon beam are underway at the $1 \mathrm{MeV}$ level.
\end{abstract}

\section{DNTRODUCTION}

The Heavy Ion Fusion Accelerator Research program at LBL is planning to construck an experimental induction linac called ILSE [1] in order to :tudy such phenomena as beam combining. bending of bunclies with velocity tilt and pulse compression. In order to build this machine, a multi-beam injector providing ions in the mass range from carbon to potassium and with paricle energy for a singly charged ion of about $2 \mathrm{MeV}$ is required. An experimental injector is under construction, however as the ILSE design evolves, its design goals will also evolve. The original design called for sixteen wo inch diamecer beams providing up to $500 \mathrm{~mA}$ of $\mathrm{C}^{+}$ions per beam. The design nomalized emitance per beam was $5 \times 10^{-7} \pi \mathrm{m} \cdot \mathrm{ral}$. The high voltage generawr, ion source. control system, and the first half of the accelerating column have been constructed and beam experiments at the $1 \mathrm{MeV}$ tevel are now occurring. We now discuss the existing system and future plans in terms of the three major components:

\section{a) High vollage puise generator \\ b) Ion source-extraction system \\ c) Accelerating column.}

\section{П. HIGH VOLTAGE PULSE GENERATOR}

This system is an unusual inductively loaded, gas insulated system designed for slow tise long pulse operation. The slow rise time is mandated by the fact that stray capacitances associated with the electrode structure in the column can cause voltage overshoot berween gaps when a fast rise pulse is

- Work supported by the Office of Energy Research. Office of Baxic Energy Sciences, U.S. Deparument of Energy. Contract DE-AC03-76:5F00098.

- Lawrence Livemore Natioral Labotatory, P.O. Box BOB. Livermore, CA 94550 appliex. The Marx circuit is loaded by placing one inductor coil in series with the Marx discharge circuit at every other capacitor-spark gap stage. The self inductance of one coil is 18 zin. The full system consists of eighteen plastic trays each containing two capacitors and two spark gaps along with associated charying resistors. The crays hang from a pair of plastic impregnated wood beams inside the pressure vessel which can contain up to 80 psig. of $\mathrm{SF}_{6}$ gas for insulation. Thus, the strucure is modularized and individual trays can be removed for servicing. One coil is mounted around each tray. At the present ime, a twelve tray system sufticient for use with the first half column is being used. The same system was used to fire into an open circuit in order to ring the discharge up to 2 MV for a dome-pressure vessel breakdown lest. The pmper loading of the inductive Marx circuit to get the desired waveform, is provided by the resistor griding structure on the column itself. This resistor is a double-helix of Tygon tubing filled with conductive water. One leg of the helix runs from ground to the high vollage terminal. The other leg renums back to ground. The conductivity of the $\mathrm{NaSO}_{4}$-water solution in the resistor is controlled by a commercial unik at a level of $27,000 \mu \mathrm{S}$ for the present configuration. According to circuit simulations, the present system is suited for operation as fast as one shou/s sec. Nomally we use it at 1 shot $/ 10-12 \sec$ for high volnge column condicioning and beam experiments. 'This raie matches the initial ILSE specification. The purpose of the slower rate is to allow additional pumping to occur inside the column.

One phenomenon observed in the Marx is a reduction of the resistance of the charge resi zors with service. The charge resistors are nominally $40 \mathrm{k} \Omega$ carbon resistor $1.675^{\circ} \mathrm{dia} . \times 12^{\prime \prime}$ long rated for $100 \mathrm{~W}$ service. These resistors were found to drop in resistance after service in the Marr. Controlled tests showed significant resistance drop when the resistors were subjected w $10 \mathrm{KV}$ pulses of the same shape as the Marx pulse. There is a tendency for the resistance to drop to some asymplotic level afier a few puises and if the voluge of the pulse is increased, the resistance will drop to a new asymptotic level.

The specifications for the high voltage generator are likely to change toward faster rise time. if column stray capacitance will permit. and toward a longer flat voltage duration. Calculations are currently being done to decermine if it is possible to reduce the rise time of the pulse applied to the column from the present $30 \mu \mathrm{sec} t 0-5 \mu \mathrm{sec}$. Finally, we are seeking to increase the rep rate capability of the system to 
$1 \mathrm{~Hz}$. Of course other factors affect the useable rep race nowably the pumping speed of the accelerating column.

\section{ION SOURCE AND EXIRACIION SYSTEM}

The ions source being used at present is a carbon vacuum are in conjunction with an electrostatic plasma confinemert device (plasma switch) 10 control emission optics during fast pulse extraction [2]. The carbon are provides sufficient ion flux for our purposes ( $>25 \mathrm{~mA} / \mathrm{cm}^{2}$ ) and in a sin ile charge state [3]. Unfortunately the trigger that initiates the arc discharge does not last more than a few tens of thousands of shots. This is due to the fact that the trigger becomes coaled with carbon over time and no remote cleaning technique has proved satisfactory ior the long itm. It is possible to change from a surface flashover trigger to a gas trigger [4] thus avoiding the carbon coating problem. However, there are other disadvancages to the source, mainly the noisy plasma from the cathode spot.

The ion source has been used together with the plasma switch in a pulsed extraction mode both in the injector itself and in a test stand. The plasma switch voltage is constant for these cests. The plasma swilch allows one wo extract quiescent beams from the source by electrostatically creating a planar virtual anode layer from which to extract ions. This means tras the extraction system dues not see the noisy streaming plasma from the cathode spor but mather a layer of ions captured by space charge forces near the plasma switch grid This advantage of quiescent extraction is affected by the fact that the electric Gelds around the wires give transverse energy to the ions which ultimately becomes added emitunce. Attempis have been made to circunvent this problem by reducing the plasma switch voluge during extraction as suggested by simulation results. The experimental result was that when the plasma switch volinge was reduced, oscillatory pulses were observed in the emittance measuring system and these pulses were not reproducible. Computer simulations were performed to determine whether or not the plasma drift velocity which tras known to exceed the Bohm velocity by -2 was responsible for this behavior. The simulations showed that the equilibrium near the switch changed but was not unstable The most probable explanation for the beam noise is that making the plasma switch transparent by lowering its vollage causes the exiractor to use the noisy streaming plasma emiued directly from the ure because the virtual anode layer is quickiy destroyed when the plasma switch volage is dropped. This technique for reducing grid induced emiluance may still work if a quiescent plasma is available for the plasma switch.

If a quiescent plasma is available the switch would be used for D.C. shutoff of the plasma from the exunction gap. When the voltage is reduced excraction would occur from the plasma behind the switch. Simulation indicates that the extraction surface should remain very close to the switch grid thus preserving the geometry of the emission surface during pulsed exaraction. We are presendy constructing a $25 \mathrm{~cm}$ diz. cusp field source which would use RF power to genemte neon ions. This source is capable of generating up to $10 \mathrm{~cm}$ dia. beams which are of interest to the IISE designers so that higher linear charge density can be generated in the beam. The gas will be admitted to the cusp chamber using a piezoelectric puff valve to reduce the acceleration column gas load. If, for some reason, the concept of reducing emittance generation by modulating the voltage on the plasma switch fails, the cusp field source would be usable for direct extraction of long pulses. If this approach is used, some way of selectively swiching the oulput pulse of the injectur must be found.

Meanwhile we continue to use the are source-D.C. plasma switch combination for tests of the injector first half column. The inherent source emituance available is $2.25 \times 10^{-6} \pi \mathrm{m}$ $\mathrm{rad}$. No further development of the arc source is anticipated because of the perceived advantages of the curp field source in extending liferime, use of inert gases, and plasma quiescence.

\section{ACCEIERATING COLUMN}

The first half of the accelerating column is designed for service at 944 KV. A drawing of the whole assembly complete with ion source and plasma switch is shown in Fig. 1. The cross hatched area represents the beam envelope as calculared with the EGUN [S] computer code for the case of $500 \mathrm{~mA} \mathrm{C}^{+}$ ions and full column voluge. The electrodes in the column are constructed of $6 \mathrm{Al} 14 \mathrm{~V}$ titanium. The ion source is located on the left. The plasma drifts from the are cathode to the plasma switch which is operated as -55 V D.C. The $1 \mathrm{~cm}$ gap w the right is called the currest valve. It is connected to a pulse line which pulses the source positively to inject a $1 \mu \mathrm{sec}$ pulse into the column at the peak of the Marx voltage pulse. At the output end of the column a long tube (3") is biased at - $3 \mathrm{kv}$ with respect to ground to keep electrons generated by background gas ionization from entering the exit of the column and being acceleraced woward the source.

The column has been operated $1010 \%$ above full design voltage without beam. In the bean excraction mode the column was first used for long pulse extraction directly from the source. For these experiments, the current valve was removed and the plasma switch grid was moved forward to the nomal position of the current valve grid. The rest of the source assembly was moved forwand by the same amourt The geometry makes it impossible to extract full current $(500 \mathrm{~mA})$ into the column and the EGUN predicted value is $\sim 300 \mathrm{~mA}$ a1 full voltage. The measured current wilh a $4^{*}$ diameter deep Faraday cup was 210-230 mA. Emituance measurements to study the optics of the bean were underaken and the results were in good agroement with EGUN. The Eact that such long current pulses at full column voltage could be cransported reliably is very encournging.

Experiments are now underway to use the current valve pulser to inject into the column. The voltage pulse is variable from 5-14 KV depending on the charge voltage of the pulse line. The voltage pulse remains unloaded by the presence of the source discharge and shows no pulse distorion. This behavior remains consjstent for a full mange of detays between the are 
discharge and the current valve pulse. Sontrol of the delay is maintained when the injector is fired as is evidenced by fibre optic monitors of the in-dome pulsers.

Initial experiments wilh the large aperture Faraday cup revealed a slow leakage current following the Mar voltage pulse and a noisy pulse at the time of the curtent valve discharge. This was verified to not be clectromagnetic noise. After trying many Faraday cup variations a fast response current transformer was instailed at the beam exit which verified the final Faraday cup results thas set electron current was exiting the column.

Experiments using a current transformer installed inside the column at the current valve exit verified that a noisy ion current pulse was entering the column. Increasing the rise time of the puise from the inidial 300 ns has showed an improvement trend. The current valve diode in $9.75 \mathrm{~mm}$ wide. Therefore a $300 \mathrm{~ns}$ rise time corresponds to several ion transit times across the gap as the design voluge of $13.6 \mathrm{KV}$ for $500 \mathrm{~mA}$ of $\mathrm{C}^{+}$ions. The rise time of the pulser had to be increased to i.s $\mu$ sec before a reasonably clean current pulse could be obtnined. Tesis using this new pulse shape are underway.

\section{REFERENCES}

[1] Induction Linac Systems Experiments, Conceptua] Enginecring Design Study, Lawrence Berkeley Laboratory, March 1989, PUB-5219.

[2] H.L. Rukowski, R.M. Johnson, W.G. Greenway, M.A. Gross, D.W. Heweth, S. Humphries Jr., Review of Sci. Inst 61, p. 553, January 1990.

[3] S. Humphries Jr. and H. Rutkowski, J. Appl. Phys. 67 . p. 3223. April 1, 1990.

[4] S. Humphries Jr., privare communicarion.

[5] W.B. Hermannsfeldc, Electron Trajectory Program, SLAC-226, November 1979.

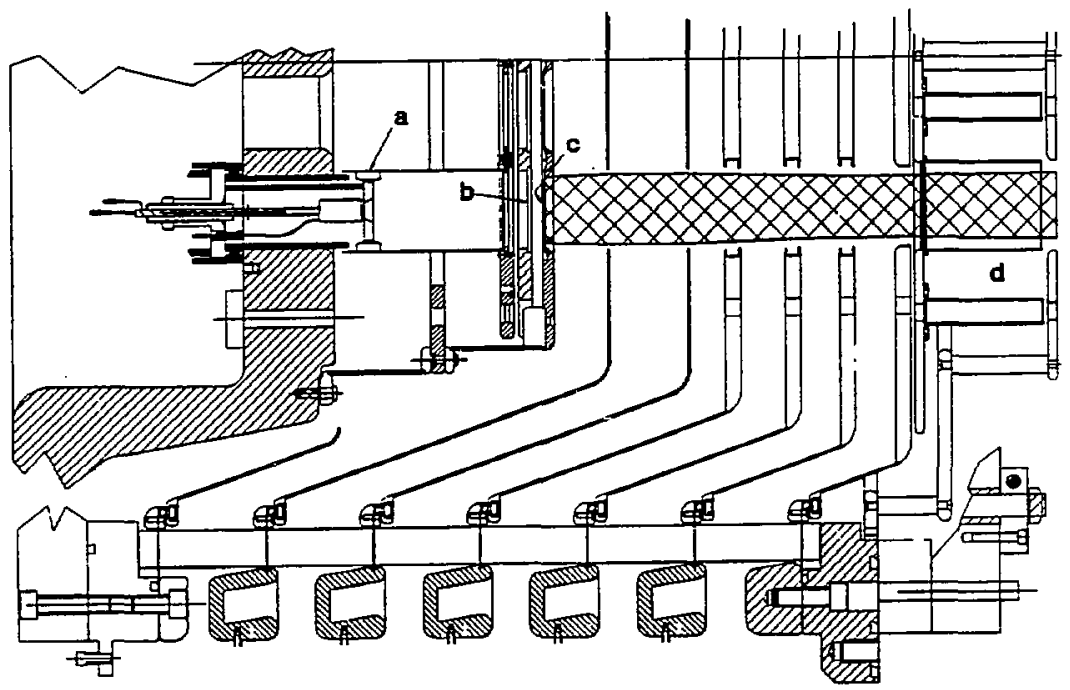

Fig. 1. First half of the full $2 \mathrm{MV}$ injector accelerating column showing a) ion sounce, b) plasma switch grid. c) current valve grid, d) electron urap. Crossharched ares is calculared beam envelope for $500 \mathrm{~mA}$, $\mathrm{C}^{+}$ions at full column voltage. 